\title{
INVOLVING DECISION-MAKERS IN THE TRANSFORMATION OF RESULTS INTO URBAN SUSTAINABILITY POLICIES
}

\author{
ELENI FELEKI*, CHRISTOS VLACHOKOSTAS, CHARISIOS ACHILLAS, \\ NICOLAS MOUSSIOPOULOS, and ALEXANDRA V. MICHAILIDOU
}

Laboratory of Heat Transfer and Environmental Engineering, Aristotle University of Thessaloniki, Thessaloniki, Greece

* Corresponding author: feleki@aix.meng.auth.gr

\section{ABSTRACT}

Mind mapping tools are used to stimulate thinking about sustainability and define its significance for urban planning. Such tools are based on keywords that are identified and structured through dialogue-based procedures. The approach can be used also for switching between highlighting sectorial aspects, such as territorial management and urban design, social and economic cohesion and cross-sectorial aspects, such as sustainable mobility and energy efficiency. This paper emphasizes a structured dialogue with desicion-makers at national, regional and local levels, aimed at identifying what decision-makers really need to decide and the key barriers to the implementation of existing urban sustainability tools. This study was organized in four discrete steps. Initially, what EU urban sustainability projects can deliver (studies, methodologies, tools, policies, etc.) was identified. The deliverables were evaluated against certain criteria and categorized into cross-cutting aspects (territorial management and urban design, social and economic cohesion) and sectorial aspects (sustainable mobility, energy efficiency). The structured dialogue was implemented in parallel with the evaluation of the deliverables in order to match them with decision-makers' needs, priorities and expectations. The ultimate goal was to develop and make available an operational Decision Support System (DSS) for public Authorities and urban planners, which combines their needs, priorities and expectations (structured dialogue results) with existing deliverables, developed within the framework of EU projects that up to now have had a low transferability and applicability rate.

Keywords: Urban sustainability policies, decision-making, structured dialogue, decision support system

doi: $10.14712 / 23361964.2016 .2$

\section{Introduction}

There are two features of a classic Mediterranean city that make it more suitable as a human habitat, while being conducive to a lower consumption of natural resources; compactness and complexity. The compactness of a city means that the buildings are grouped closely together, creating a dense environment and a sufficient critical mass of people that there is a high level of different activities, and therefore a transfer of information and relationships. Complexity goes hand in hand with compactness and reflects the diversity of human activities that are located in different parts of the city.

The idea of sustainability in urban models involves the interplay of territorial actions on the city configuration combined with environmental and landscaping elements and the optimal management of natural resources, while promoting social cohesion and the participation of citizens (Perry and May 2010; Perry 2013). It is not possible to work on a part of an urban mosaic, without taking into account its effect on other elements, thus holistic urban planning is a crucial process.

Urban planning is a multidisciplinary scientific and political process for regulating urban development taking into account other components of the urban environment (transport, green spaces, etc.). On this basis, urban planning addresses the real needs and capacities of a city. Planning enables stakeholders to visualize alternative future scenarios that are more sustainable, economically productive and responsive to trends and challenges, and facilitate decision-making and mobilization and empowerment of communities. Urban planning can also promote more efficient, eco-friendly cities through the densification of urban settlements and of mixed land-use, the integration of infrastructure, housing services and the careful shaping of public spaces as well as natural urban areas (Hodson and Marvin 2010).

Decision support tools are essential for producing an urban development strategy for a city, which is mapped out for all those who live, work, invest and interact with all kinds of activities in the city, as well as for visitors and many others. Dialogue-based methods (structured dialogue) for decision-making by politicians and citizens on the formulation of an urban sustainability strategy clearly take preference in this process.

\section{Methodology}

A structured dialogue is a process implemented with decisions-makers in order to identify sustainable urban policies and the barriers encountered in implementing European urban policies and their national adaptations. It aims to identify what decision-makers really need and the key barriers to the implementation of sustainable urban policies in the EU (Reed et al. 2006).

This process was used by a research team at the Aristotle University in Thessaloniki, in an effort to help de- 
cision-makers adopt existing tools, methodologies and policies within the framework of EU projects and key European initiatives that can be effectively and easily used to meet their needs and priorities in the field of urban sustainability. A mechanism (methodology) was developed and followed in order to support the transferability and applicability of deliverables by the decision-makers.

Based on this methodology, three decision-makers, related to the same kind of sustainable urban policy, were selected by the research team. This avoids getting lost in many different policies and enabled the decision makers to focus on one specific aspect (either sectorial or cross-sectorial). The sectorial aspects were: territorial management and urban design, social and economic cohesion. The cross-sectorial aspects were sustainable mobility and energy efficiency. The specific sectorial aspects where selected for two reasons: (i) They are aspects of vital importance for the transformation of results into urban sustainability policies in Mediterranean cities and (ii) They are top priorities in the scientific and political process for regulating urban development in the study area: Thessaloniki, Greece.

\section{Criteria for Selecting the Decision-Makers}

Decision-makers were very carefully selected based on the following criteria:

(i) Responsibility and influence: Decision-makers should be politicians (elected representatives, who can draft policies) or high-level public administrators (people in charge of urban projects, like new areas and developments, who can implement the policies sector by sector). According to the methodology, both politicians and high-level administrators should be selected.

(ii) Field of competence: Two options were offered, as follows:

- As the interviewer might be interested specifically in some deliverable projects, decision-makers with knowledge of these topics could be chosen.

- Interviewers could also choose decision-makers that are not experts in those topics, but knowledgeable about current trends in urban sustainability policies.

(iii) Decision-making level: All levels (national, regional, local) should be represented.

(iv) Political diversity: As sustainable urban policies depend also on ideological points of view, the political parties present in the European Parliament should also be represented.

\section{Holding of Interviews with Decision-Makers}

The structured dialogue was based on a Questionnaire containing both closed and open-ended questions. The main fields of the Questionnaire dealt with the following issues:

(i) Policies for urban sustainability in general: the most important urban problems in the political or technical agenda were discussed. The following policy areas were ranked: energy efficiency in buildings, sustainable transport, sustainable urban planning, lighting, waste, economic development, architectural heritage, according to the decision maker's view.

(ii) Application of European legislation on urban sustainability: Problems that hinder the implementation of European legislation affecting urban sustainability aspects were discussed.

(iii) Barriers about sustainable urban policies, among: - Internal barriers in the administration such as technical/lack of competence, financial barriers, regulatory and legislative barriers, lack of governance tools, lack of partnership and organisational instruments to support the involvement of different social actors, wrong policies with respect to urban problems.

- Political barriers, such as opposition of some representatives and lack of political support, change of political agenda, conflicts between the priorities of the different decision-makers.

- External barriers, such as acceptability by citizens and the beneficiaries of the actions and the different priorities of the people involved, economic crises that can change expectations of people, weak instruments and methods to involve citizens.

(iv) Needs and expectations about policies for urban sustainability: In this section, which is crucial for decision support, priority is given to issues that decision-makers wish to improve or focus on, in order to enhance the policies they wish to implement. In addition, the needs of decision-makers for developing urban sustainability policies, e.g. in selecting different typologies of instruments, such as incentives, direct actions, taxes, rules, voluntary instruments, personnel, competences, innovative instruments, funds, etc., were discussed. Availability of finance or tools with long-term effects or to resolve immediate urban problems and/or emergencies were exposed. Existing European activities and initiatives addressing the constraints and needs previously expressed were discussed as well as suggestions for the next program to support some priorities and policies for 2014-2020.

\section{Decision Support Tool}

The results of the structured dialogue are the main input for the Decision Support Tool used to support the transferability-capitalization of outputs of former EU projects to the decision-makers. An operational platform, the main feature of the tool, was developed and used. The 
platform is an operational instrument/interface that has the ability to enhance the transferability of current and future results developed within the framework of EU projects, in a comprehensible and practical way and according to decision-makers' needs and priorities, previously recorded during the structured dialogue process.

A series of outputs - deliverables (either studies, or tools, methodologies, etc.) developed within the framework of EU projects that can be transferred and used by other cities aiming to enhance sustainable urban development are selected and categorized in respect to four axes: (i) territorial management and urban design, (ii) social and economic cohesion, (iii) mobility and transport, (iv) energy efficiency. Both the structured dialogue approach and the outputs in the platform of the DSS are determined by the same urban sustainability definition. The deliverables are categorized by type, being policy papers, or operational tools, or best practices or guidelines, approaches, methodological schemes, etc. Then, considering a set of transferability criteria and the realistic needs and priorities as expressed by decision makers at the national, regional and local levels the results are evaluated by a Scientific Committee (experts from different disciplines and nationalities under a transnational common strategy).

Based on the above, the capitalization platform of the DSS includes EU project deliverables, re-organized and reformulated according to decision-makers' priorities, in order to offer solutions or to improve policies able to mitigate their problems.

The research of the team at the Aristotle University of Thessaloniki, can be depicted schematically as in Fig. 1.

Based on the above a structured dialogue was held for the region of Central Macedonia located in the northern part of Greece, between the Aristotle University Thessaloniki's research team and the following representatives:

(i) President of the Organization of Planning and Environmental Protection of Thessaloniki, representing the national level.

(ii) High-level administrator in charge of the permanent committee for spatial and urban planning and development of the Technical Chamber, department of Central Macedonia, representing the regional level.

(iii) Deputy Mayor of the City of Thessaloniki, representing the local level.

The most important common barriers affecting the implementation of sustainable urban policies identified by all three levels of political governance were:

- Non-existence of a strong political vision for the cities.

- Lack of metropolitan governance - flexibility and cooperation between local and regional administrations (lack of administrative integration).

- Non-implementation (or low implementation) of existing tools for metropolitan governance.

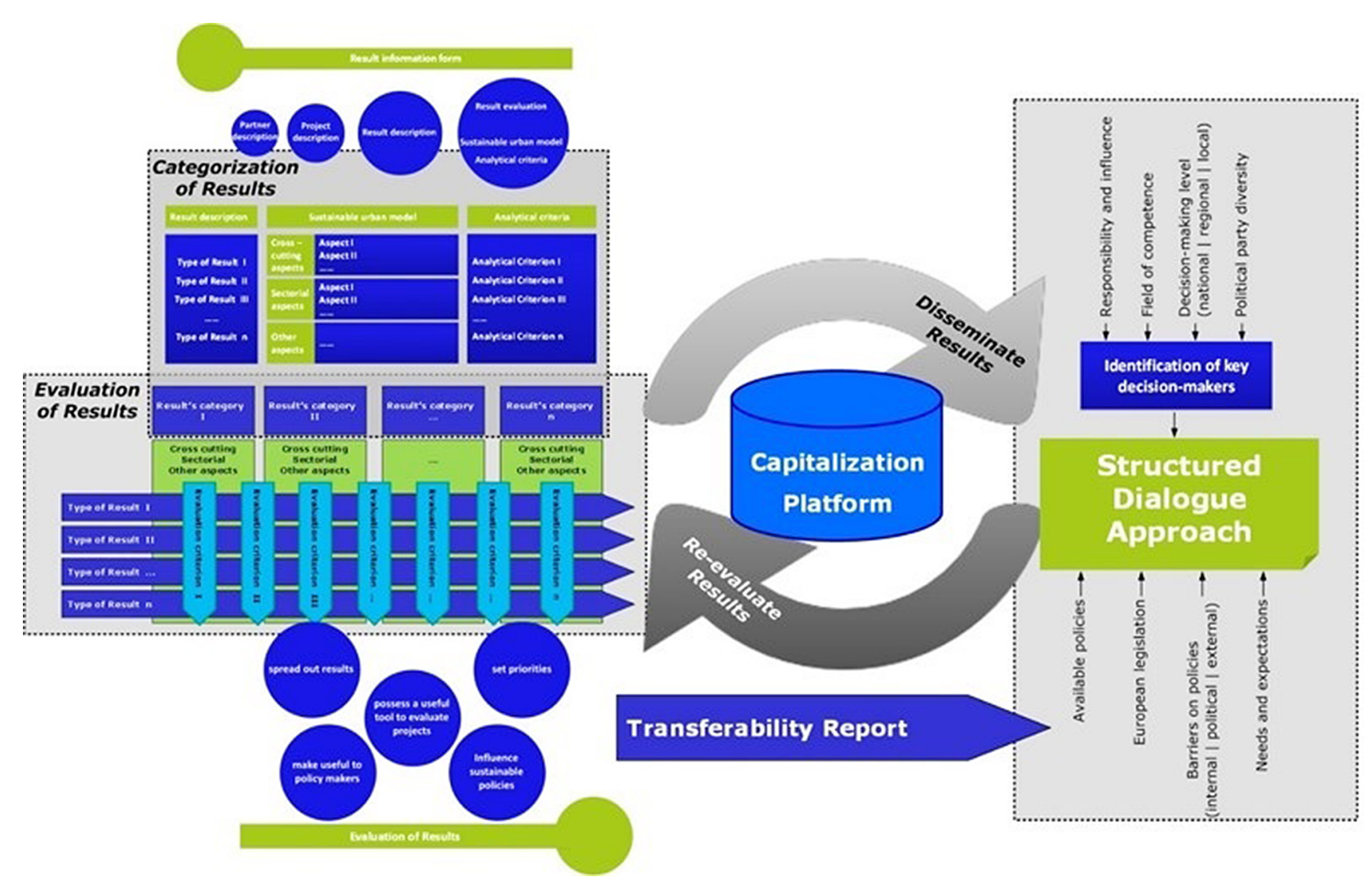

Fig. 1 Schematic approach of the DSS for public Authorities and urban planners. 
- Financial issues (low ability to finance urban sustainability projects in cities).

- Conflicts between national regulations (from different Ministries).

- Inability of regional and local administrators to formulate and/or modify the regional, local regulatory framework, and adjust it to the regional and local needs, respectively.

- Opposition of some participants, due to conflicts between priorities of different decision makers.

- Weak methods of involving and mobilizing citizens.

- Lack or wrong policies concerning sustainable development.

- Financial crises that lead cities to deal with different priorities.

The suggestions expressed by the representatives are summarized as follows:

- Enhancement of metropolitan governance and use of existing tools.

- Strengthening of the role of local and regional government, by increasing resources and institutional responsibilities.

- Better collaboration between local and regional authorities and replacement of out of date bodies with more flexible schemes.

- Continuity and consistency in administration, regardless of changes in personal, by means of permanent mechanisms for monitoring the implementation of agreed projects at national or local level.

- Better coordination - the legislative initiatives of different Ministries should not be contradictory.

- Strengthening and establishment of methods for increasing social acceptance of different projects, public consultation, promotion and dissemination of good policies, rewards for effective citizen participation, etc.

All decision-makers agreed that there is great need for enhancement of the metropolitan governance and common decision making based on a clear vision for a city and for better use of the existing financial tools. Collaboration between different economic interests in the exploitation of new funding mechanisms is also of great importance. In terms of financing, the difficulties in optimizing its use, is linked to the poor administrative coordination between Authorities, slow spreading of information, "tight" deadlines, immature proposals and lack of specialized human resources for the timely preparation of proposals. Also, the bureaucratic proce- dures and the institutional and legal framework affect the ability to utilize the available financial sources.

\section{Conclusions}

This paper introduces and depicts a way of setting and managing policy priorities in urban planning. According to the results of the structured dialogue involving decision-makers representing national, regional and local levels in the area of Central Macedonia in Greece, the main findings regarding the national level is the need for the introduction of EU policies that address spatial management in a holistic way. Individual components, such as microclimate, desertification, etc., exist in the regulatory framework, but there is lack of an integrated approach. Also, there is a gap at the national policy level for urban and peri-urban landscapes. At the regional level there is a need to increase mobility and remove obstacles to the transfer of employees and goods, which would enhance the means of transportation within the region of Central Macedonia and the wider buffer zone. Also there is a need for prevention and management of natural disasters (floods, forest fires, earthquakes). Finally, at the local level the improvement of the economic environment and the enhancement of social cohesion are of great importance as well as the promotion of local products and initiatives. The results of the structured dialogue were used to assess the transferability of outputs from EU urban sustainability projects. In this respect, the DSS where the former outputs are categorized and uploaded serves as a platform for public Authorities and urban planners that seek solutions to transform them into urban sustainability policies.

\section{REFERENCES}

Hodson M, Marvin S (2010) Mediating low carbon urban transitions. American Association of Geographers Conference, Sustainable Practices Research Group. Washington, DC, USA.

Perry B (2013) Governing sustainable urban communities? The Uses and Abuses of Community for Sustainable Development Seminar. Sustainable Practices Research Group. Leeds, UK.

Perry B, May T (2010) Re-thinking sustainable urbanism: what knowledge and how? Regional Studies Association Winter Conference Regions and the Environment. Regional Studies Association, London.

Reed MS, Fraser EDG, Dougill AJ (2006) An adaptive learning process for developing and applying sustainability indicators with local communities. Ecol Econ 59: 406-418. 